\title{
Thermal effects in PZT: diffusion of titanium and recrystallization of platinum
}

\author{
Ching-Liang Dai ${ }^{\mathrm{a}, *}, \mathrm{Fu}^{-Y u a n} \mathrm{Xiao}^{\mathrm{b}}{ }^{\mathrm{b}}$, Chi-Yuan Lee ${ }^{\mathrm{c}}$, Ying-Chou Cheng ${ }^{\mathrm{c}}$, \\ Pei-Zen Chang ${ }^{d}$, Shuo-Hung Chang ${ }^{c}$ \\ ${ }^{a}$ Department of Mechanical Engineering, National ChungHsing University, 402 Taichung, Taiwan, ROC \\ b National Chip Implementation Center, HsingChu 300, Taiwan, ROC \\ ${ }^{c}$ Department of Mechanical Engineering, National Taiwan University, 106 Taipei, Taiwan, ROC \\ ${ }^{\mathrm{d}}$ Institute of Applied Mechanics, National Taiwan University, 106 Taipei, Taiwan, ROC
}

Received 10 November 2003; received in revised form 12 May 2004

\begin{abstract}
This paper shows temperature dependent hillocks and cracks on the piezoelectric thin film lead-zirconate-titanate (PZT). The PZT thin film is deposited on $\mathrm{Pt} / \mathrm{Ti} / \mathrm{SiO}_{2} / \mathrm{Si}$ substrate by metal organic decomposition (MOD) where platinum is a bottom electrode and titanium is an adhesive layer. Experimental results demonstrate that if the annealing temperature exceeds $700{ }^{\circ} \mathrm{C}$, titanium diffuses into the platinum layer, and platinum recrystallizes. In addition, partially volatilizable solution in PZT evaporates and thus, causes volume change and residual stresses. Hillocks and cracks in PZT are primarily caused by the above-mentioned thermal effects and make the top electrode and the bottom electrode electrically short. Two methods are applied to improve the thermal effects of platinum and titanium. PZT thin film with perovskite structure is well characterized by X-ray diffractometer (XRD) and a hysteresis loop. The remnant polarization is $20.448 \mu \mathrm{C} / \mathrm{cm}^{2}$, and the coercive field is $183.299 \mathrm{~V} / \mathrm{cm}$. The resonant and anti-resonant frequencies are 14.95 and $20.2 \mathrm{kHz}$, respectively. The piezoelectric constants, $d_{31}$ and $d_{33}$, and the electromechanical coupling coefficient are $159.57 \mathrm{pC} / \mathrm{N},-72.86 \mathrm{pC} / \mathrm{N}$, and 0.672 , respectively.
\end{abstract}

(C) 2004 Elsevier B.V. All rights reserved.

Keywords: PZT; MOD; Thermal effects; Hillocks; Cracks

\section{Introduction}

The piezoelectric ceramics lead-zirconate-titanate (PZT) fabricated by sol-gel [1-3], metal organic decomposition (MOD) [4-6], metal organic chemical vapor deposition (MOCVD) [7,8], laser ablation [9-11], and radio frequency (RF) sputtering [12-14], are successfully integrated into silicon-based microelectromechanical system (MEMS), especially for application in sensors and actuators [15]. The advantages of PZT thin film are excellent electrostrictive property, fast response, high sensitivity, low electric noise, low driving voltage, and high-force output. Compared with other technologies, MOD offers greater compositional control, lower facility requirements, and higher throughout, and thus, flexibly supports optimization of film properties.

\footnotetext{
* Corresponding author. Tel.: +886 $42840433 \times 423$; fax: +88642877170 .

E-mail address: cldai@dragon.nchu.edu.tw (C.-L. Dai).
}

The last step of MOD is high temperature annealing. The goal of this annealing process is to transform the phase of PZT from amorphous to perovskite. Unfortunately, in the meantime, inevitable volume reduction, diffusion of titanium and recrystallization of platinum induce large stress in PZT thin film. Because of the large internal stress, cracks and deformation occur in PZT thin film. In order to alleviate the thermal reaction in titanium and platinum, annealing temperature must be carefully controlled. Previous works [4-6] focus on the recipe of PZT solution and its performance. In this work, the thermal effects of titanium and platinum in PZT will be discussed.

In this study, PZT is deposited on $\mathrm{Pt} / \mathrm{Ti} / \mathrm{SiO}_{2} / \mathrm{Si}$ substrate by MOD. The silicon dioxide $\left(\mathrm{SiO}_{2}\right)$ acts as a diffusion barrier layer that prevents titanium atoms from diffusing into silicon substrate. The titanium layer is an adhesion layer for platinum. The platinum functions as the stable bottom electrode with a good lattice constant match to the PZT (llll) surface. The PZT thin film exhibits cracks and hillocks under 




Fig. 1. Fabrication procedure of PZT.

high temperature annealing. These cracks and hillocks cause electric shorting of the sensors and actuators. Understanding the thermal effect during annealing is important for fabricating a better ferroelectric thin film. Many material tests such as scanning electron microscope (SEM), atomic force microscope (AFM), tunneling electron microscope (TEM), energy dispersive analysis of X-ray (EDAX), auger electron spectrometry (AES), and electron spectroscopy for chemical analysis (ESCA) are used to analyze and evaluate these effects. Experimental results show that if the annealing temperature exceeds $700^{\circ} \mathrm{C}$, cracks and hillocks appear on the surface of PZT, due to Pt/Ti thermal effects. Two methods are applied to improve the thermal effects of platinum and titanium. PZT thin film with perovskite structure is well characterized by XRD and a hysteresis loop. The piezoelectric constants, $d_{31}$ and $d_{33}$, and the electromechanical coupling coefficient are $159.57 \mathrm{pC} / \mathrm{N},-72.86 \mathrm{pC} / \mathrm{N}$, and 0.672 , respectively. The remnant polarization is $20.448 \mu \mathrm{C} / \mathrm{cm}^{2}$, and the coercive field is $183.299 \mathrm{~V} / \mathrm{cm}$. The resonant and anti-resonant frequencies are 14.95 and $20.2 \mathrm{kHz}$, respectively.

\section{Fabrication procedure}

Metal organic decomposition is employed to fabricate the PZT thin film. Fig. 1 shows the total fabrication procedure. First, $1 \mu \mathrm{m}$ silicon dioxide is grown as a diffusion barrier

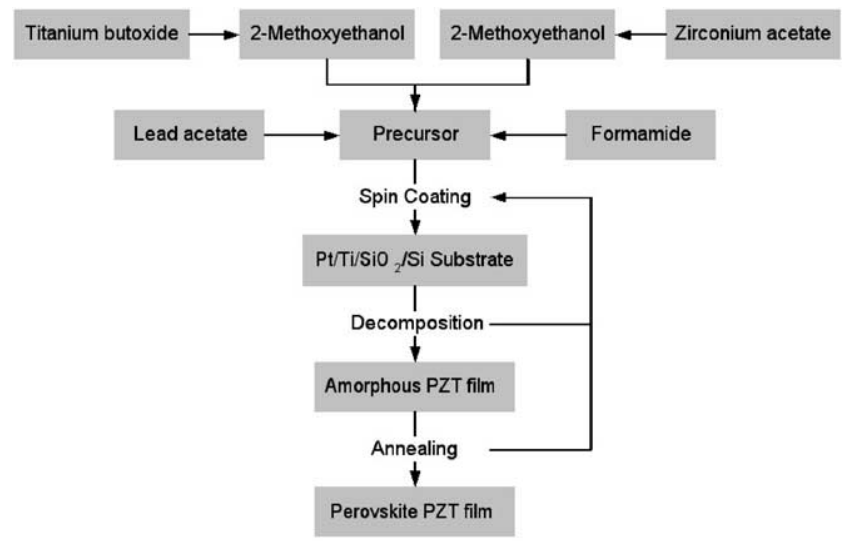

Fig. 2. Detailed process flow of metal organic decomposition.

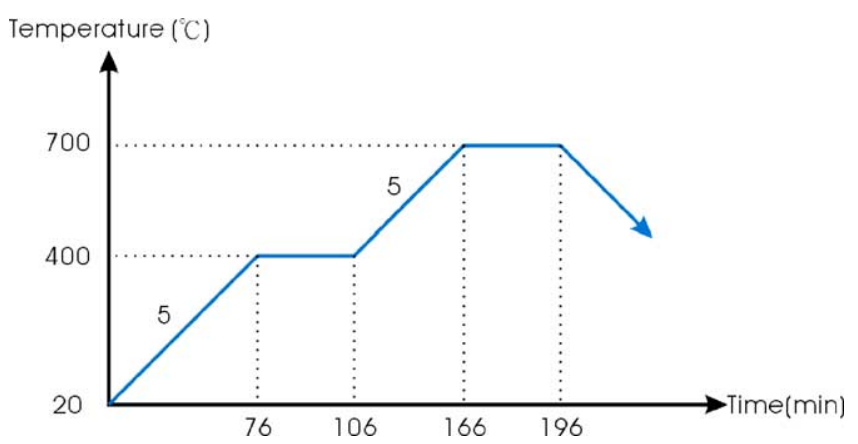

Fig. 3. Annealing temperature cycle.

layer on a single crystal silicon substrate by thermal oxidation. Second, $200 \AA \AA$ titanium and $1500 \AA$ Alatinum are deposited in turn by thermal evaporation. Finally, PZT is coated on platinum by MOD. Fig. 2 shows the detailed process flow of MOD. The precursor, including 2-methoxyethanol titanium butoxide, 2-methoxyethanol zirconium acetate, lead acetate, and formamide, is coated on the $\mathrm{Pt} / \mathrm{Ti} / \mathrm{SiO}_{2} / \mathrm{Si}$ substrate. The substrate is then heated at $200^{\circ} \mathrm{C}$ for $5 \mathrm{~min}$. The above steps are repeated to five times so as to increase the thickness of PZT. According to the annealing temperature cycle as shown in Fig. 3, PZT thin film is annealed to complete the phase change from amorphous to pervoskite. Table 1 shows material properties of lead acetate, titanium butoxide, and zirconium acetate, and their recipes. Excess lead acetate is required, since annealing causes a loss of lead. The ratio of zirconium to titanium is 53/47 at the morphotropic phase boundary.

Table 1

Properties and recipes of PZT solution

\begin{tabular}{llll}
\hline Name & Lead acetate & Zirconium acetate & Titanium butoxide \\
\hline Molecular formula & $\mathrm{Pb}\left(\mathrm{CH}_{3} \mathrm{COO}\right)_{2} \cdot 3 \mathrm{H}_{2} \mathrm{O}$ & $\mathrm{Zr}(\mathrm{OH})_{2}(\mathrm{CH} 3 \mathrm{COO})_{2}$ & $\mathrm{Ti}\left(\mathrm{O}\left(\mathrm{CH}_{2}\right)_{3} \mathrm{CH}_{3}\right)_{4}$ \\
Molecular weight & 379.33 & 243.224 & 340.36 \\
Concentration & $99.50 \%$ & $15 \%$ & $97 \%$ \\
Density $\left(\mathrm{g} / \mathrm{cm}^{3}\right)$ & $\mathrm{Solid}$ & 1.279 & 0.995 \\
Mole numbers & $1 / 1.05 / 1.10$ & 0.53 & 0.47 \\
Equivalent mass/volume & $5.29 / 5.56 / 5.82(\mathrm{~g})$ & $3.5(\mathrm{ml})$ & $2.3(\mathrm{ml})$ \\
\hline
\end{tabular}




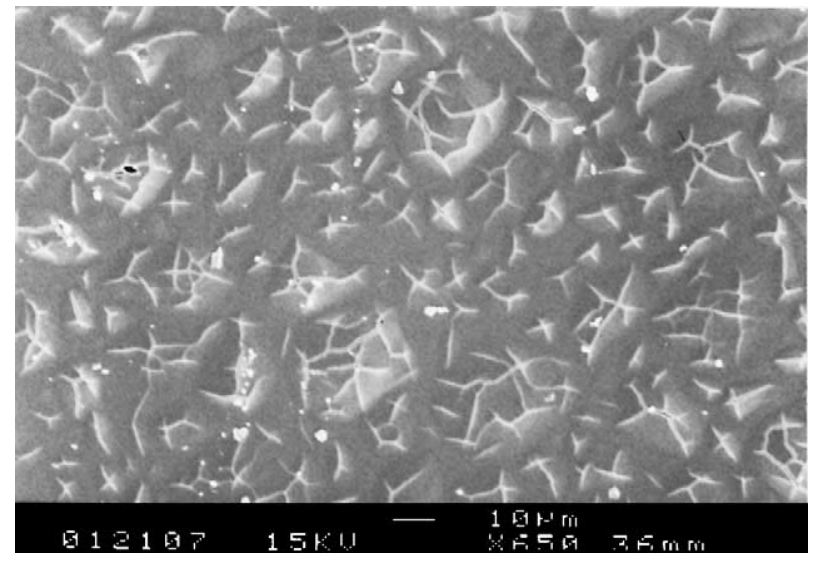

Fig. 4. Surface profile of PZT after annealing at $750{ }^{\circ} \mathrm{C}$.

\section{Results and discussion}

\subsection{Pt/Ti thermal effect}

The surface profiles of PZT after annealing at $750{ }^{\circ} \mathrm{C}$ are shown in Figs. 4 and 5. It is easy to see that many cracks and hillocks appear on the surface. It should be noted that hillocks result in cracks. There are three factors that can cause hillocks. One is the volume reduction of the PZT solution while annealing, and thus, PZT contracts and deforms. Another is the change of grain size of the bottom electrode Pt due to recrystallization. The other is the thickness variation in platinum due to titanium diffusion. In order to prove the second point of view, a $\mathrm{Pt} / \mathrm{Ti} / \mathrm{SiO}_{2} / \mathrm{Si}$ substrate is annealed in the same temperature cycle as shown in Fig. 6(b). The average dimension of recrystallized grains shown in Fig. 6(b) is approximately $1 \mu \mathrm{m}$. Compared with Fig. 6(a), the grain

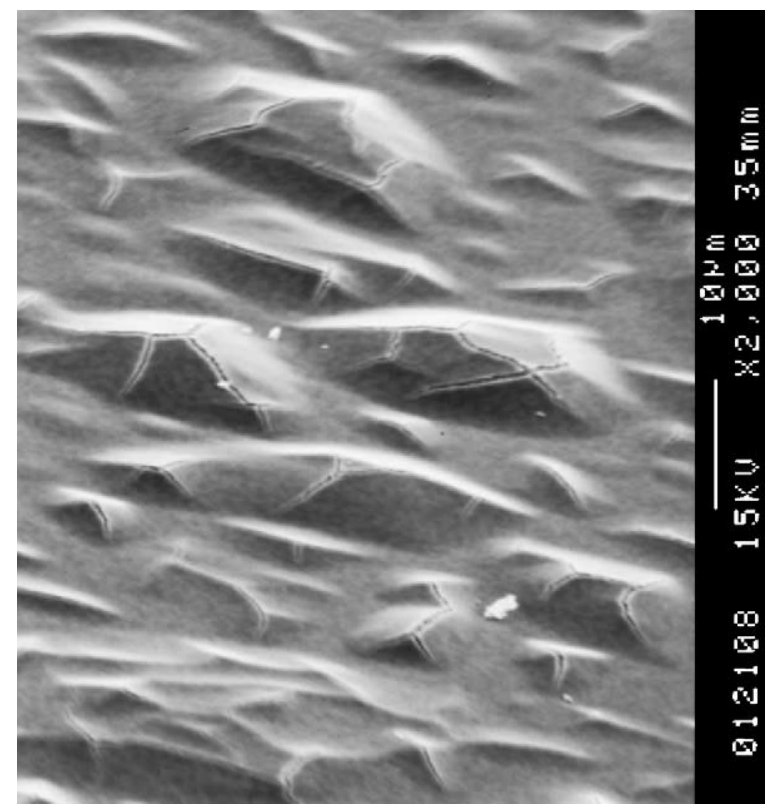

Fig. 5. Magnification of cracks and hillocks on the surface of PZT. size is apparently larger. The surface roughness of Fig. 6(b) is measured by AFM as shown in Fig. 7. The average surface roughness is $222 \AA$ and the height of grains mostly ranges from 500 to $1200 \AA$, which is smaller than original film thickness and is reasonable. The next step is to prove that the white grains shown in Fig. 6(b) are recrystallized platinum. Both AES and ESCA can be used to analyze the composition of particles on surface. Figs. 8 and 9 show the measured results and demonstrate that the composition of the white grains is platinum. Fig. 10 shows the surface profiles of platinum and PZT before and after various annealing temperatures. It is obvious that the grain size depends on the annealing temperature, and the higher the temperature is, the larger the grain size is. Recrystallized grains make PZT form hillocks and cracks.

Titanium should also be noted due to high diffusion rate. To observe this phenomenon, Fig. 11 shows the TEM and EDAX analyses of the annealed $\mathrm{Pt} / \mathrm{Ti} / \mathrm{SiO}_{2} / \mathrm{Si}$ substrate. The boundary between titanium and platinum is ambiguous. Evidently, titanium diffuses into platinum and thus, makes the surface of platinum rough and uneven. This effect also causes hillocks and cracks in PZT.

There are two methods to improve the thermal effects of platinum and titanium. One is increasing the thickness of

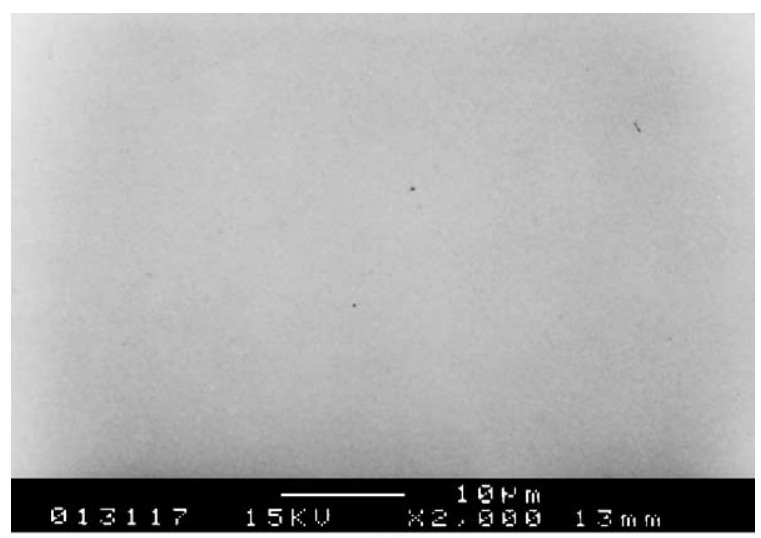

(a)

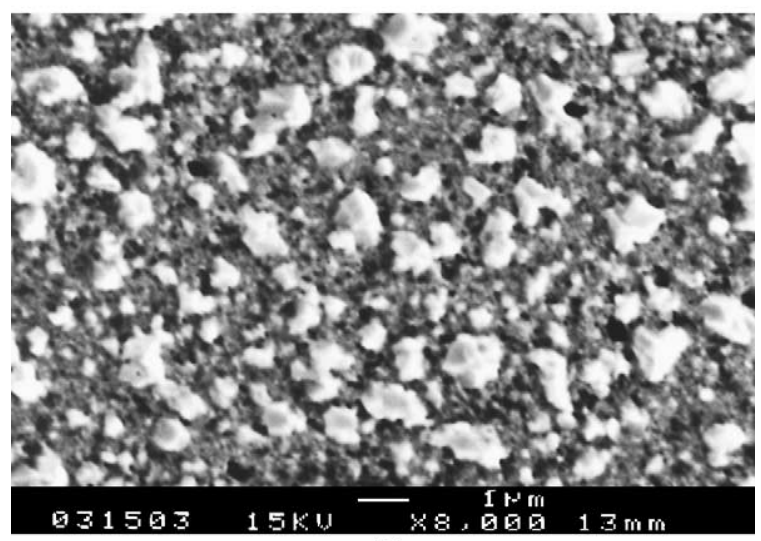

(b)

Fig. 6. (a) Surface profile of Pt before annealing; (b) recrystallization of $\mathrm{Pt}$ after annealing at $750^{\circ} \mathrm{C}$. 

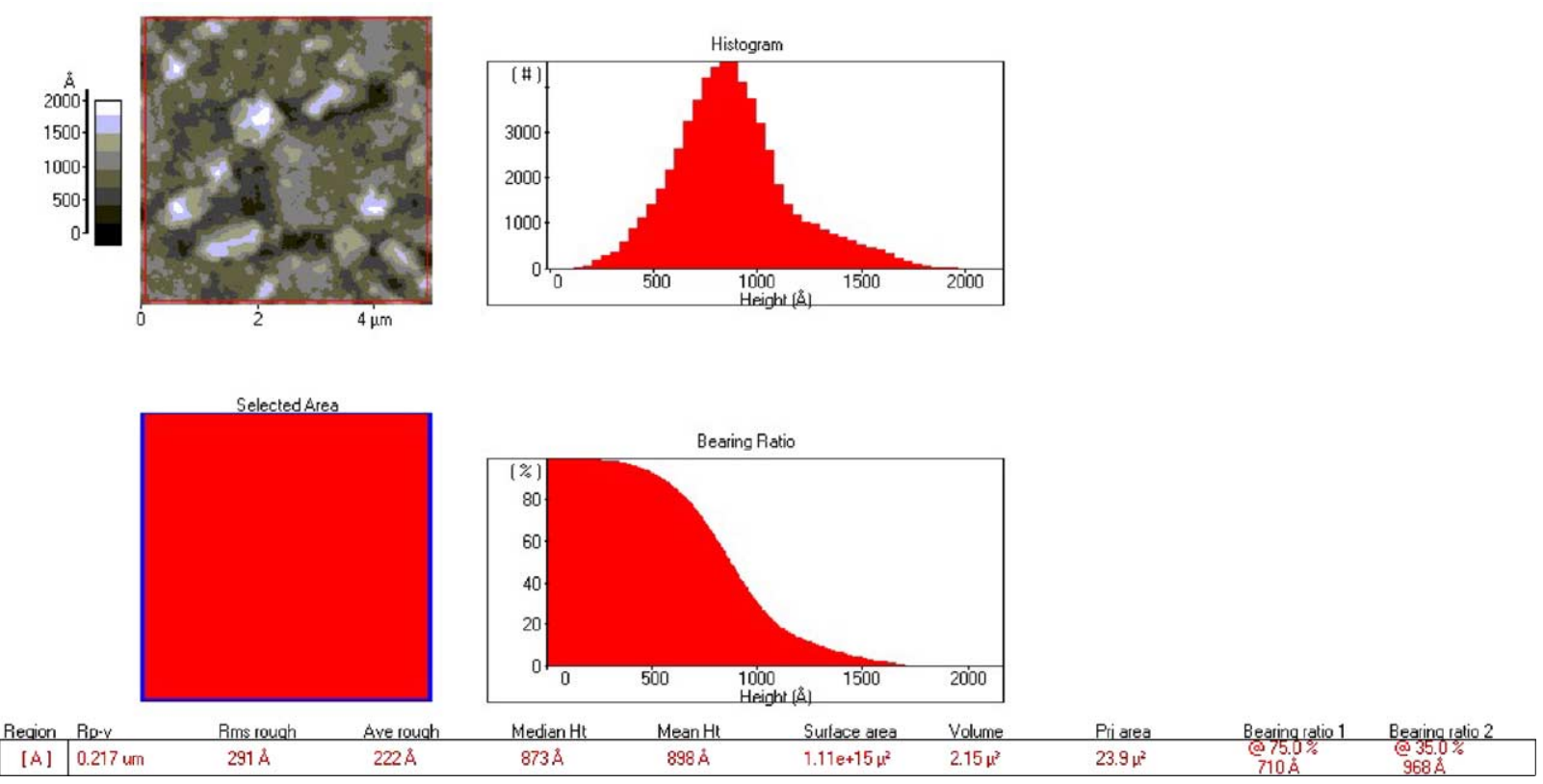

Fig. 7. AFM surface roughness measurement of Fig. 6(b).

platinum as shown in Fig. 12. It is significant that the grain size becomes much smaller when the thickness of platinum increases to $2500 \AA$. The other is to optimize the process parameters of platinum and titanium. As shown in Fig. 13, high quality of platinum and titanium effectively reduces recrystallization of platinum and diffusion of titanium. Hillocks and cracks almost disappear at $700{ }^{\circ} \mathrm{C}$.

\subsection{Characteristics of PZT thin film}

\subsubsection{X-ray diffractometer}

Fig. 14 shows the XRD spectra of Pt at different temperatures. The intensity of Pt (1 111$)$ increases with temperature. Pt (1 111 ) is helpful to form PZT (1 111 ) due to similar lattice constants. Fig. 15 indicates the orientation of PZT. The

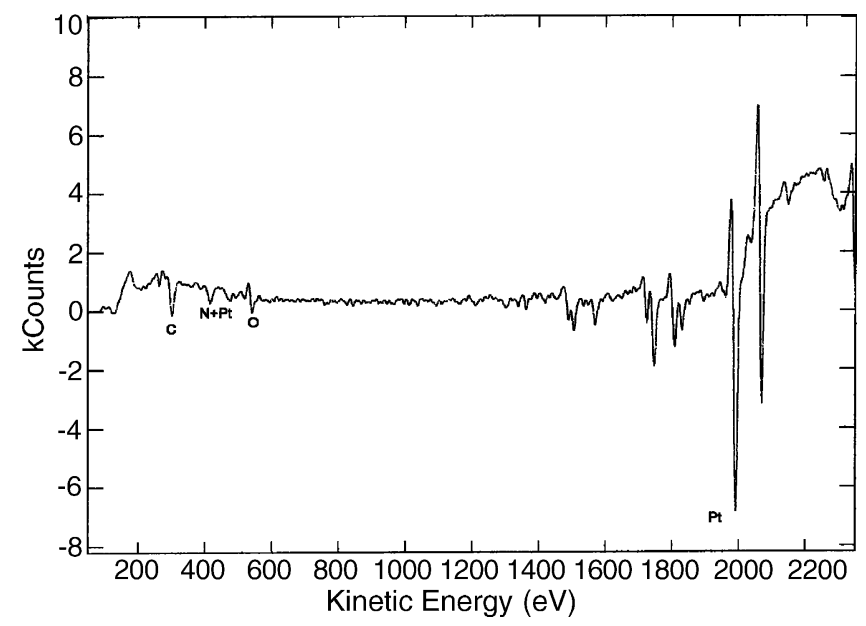

Fig. 8. AES analysis of white grains shown in Fig. 6(b).
Perovskite phase of PZT can be verified by PZT (1 111$)$ orientation. The greater intensity of PZT ( $\left.\begin{array}{llll}1 & 1 & 1\end{array}\right)$ corresponds to better piezoelectricity.

\subsubsection{Hysteresis loop}

The hysteresis loop can be measured using a ferroelectric test system RT66A, as shown in Fig. 16. A virtual ground mode is used instead of a sawyer tower mode due to the presence of an external sensing capacitor and the parasitic effect. The input voltage, saturation polarization, remnant polarization, and coercive field are $10 \mathrm{~V}, 21.145 \mu \mathrm{C} / \mathrm{cm}^{2}$, $20.448 \mu \mathrm{C} / \mathrm{cm}^{2}$, and $183.299 \mathrm{~V} / \mathrm{cm}$, respectively. Since the remnant polarization is proportional to piezoelectric constants, larger remnant polarization corresponds to a stronger piezoelectric effect.

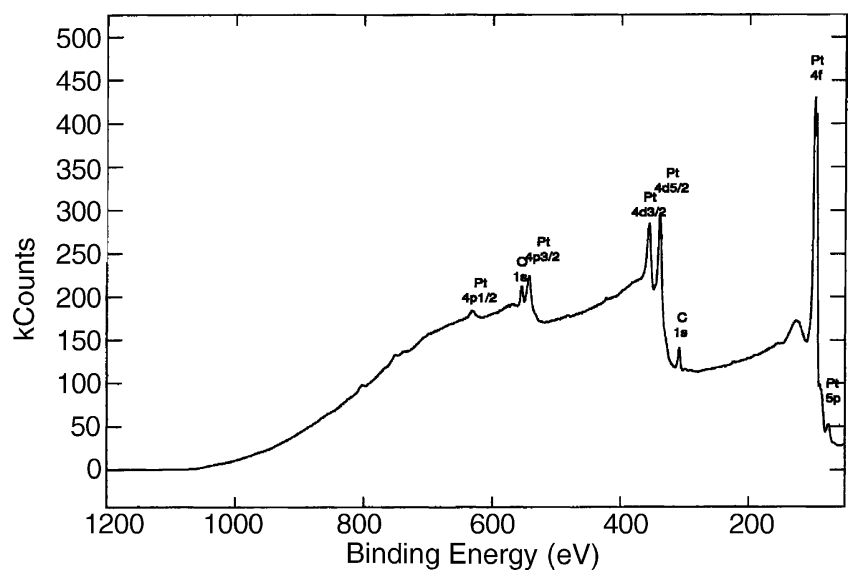

Fig. 9. ESCA analysis of white grains shown in Fig. 6(b). 


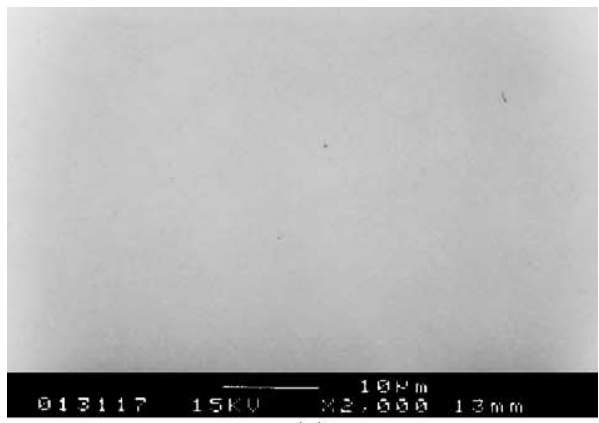

(a)

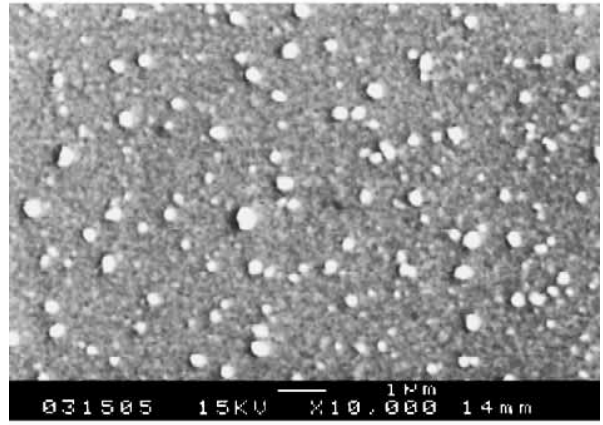

(b)



(c)

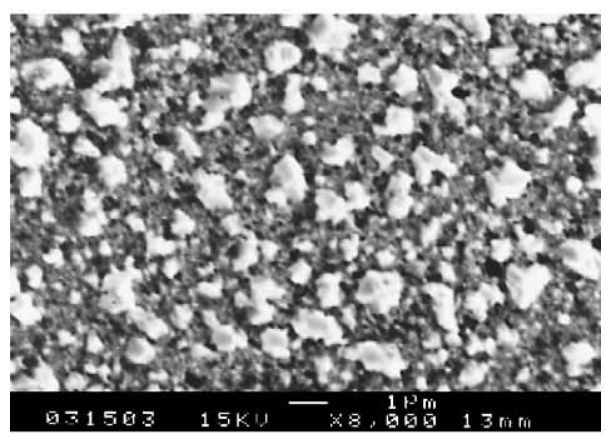

(d)

Fig. 10. Surface profiles of Pt: (a) before annealing and after annealing at (b) $650{ }^{\circ} \mathrm{C}$ (c) $700^{\circ} \mathrm{C}$ and (d) $750{ }^{\circ} \mathrm{C}$.

\subsubsection{Electromechanical coupling coefficient}

The electromechanical coupling coefficient of PZT can be expressed as [16,17]:

$k_{\mathrm{d}}=\sqrt{\frac{f_{\mathrm{a}}^{2}-f_{\mathrm{r}}^{2}}{f_{\mathrm{a}}^{2}}}$



Fig. 11. Cross section view of annealed $\mathrm{Pt} / \mathrm{Ti} / \mathrm{SiO}_{2} / \mathrm{Si}$ substrate.



Fig. 12. Surface profile of $2500 \AA \mathrm{Pt}$ after annealing at $750^{\circ} \mathrm{C}$.

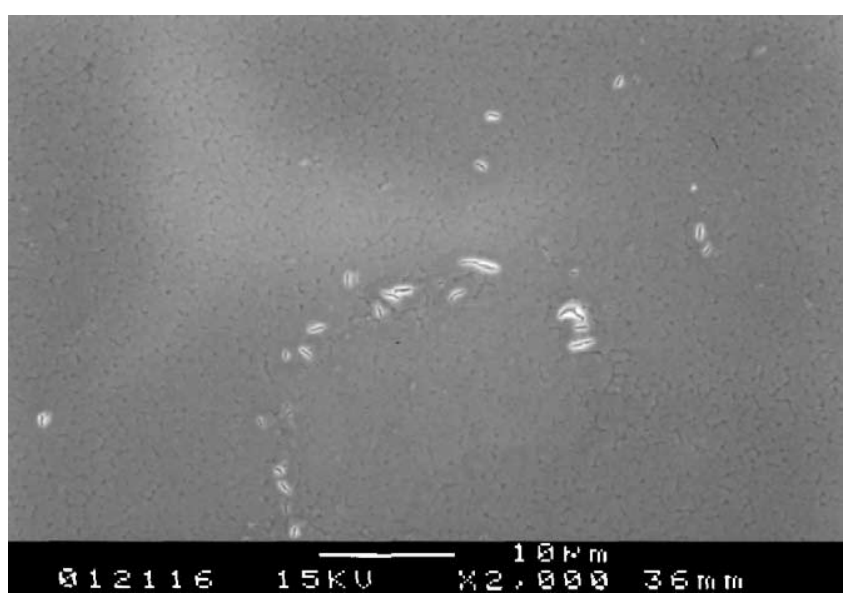

Fig. 13. Surface profile of PZT after annealing at $700^{\circ} \mathrm{C}$. 



Fig. 14. XRD spectra of Pt at various temperatures: (a) $600{ }^{\circ} \mathrm{C}$ (b) $650{ }^{\circ} \mathrm{C}$ (c) $700^{\circ} \mathrm{C}$ and (d) $750{ }^{\circ} \mathrm{C}$.

where $k_{\mathrm{d}}$ is the electromechanical coupling coefficient; $f_{\mathrm{a}}$, the anti-resonant frequency and; $f_{\mathrm{r}}$, the resonant frequency. $f_{\mathrm{a}}$ and $f_{\mathrm{r}}$ measured by an impedance analyzer HP4194A are 20.2 and $14.95 \mathrm{kHz}$, respectively. From Eq. (1), $k_{\mathrm{d}}$ can be calculated as 0.672 .

\subsubsection{Dielectric constant and piezoelectric constants}

The dielectric constant of PZT can be determined from the equation of a parallel-plate capacitor:

$\varepsilon_{\mathrm{r}}=\frac{C d}{\varepsilon_{0} A}$

where $\varepsilon_{\mathrm{r}}$ is the dielectric constant of PZT; $\varepsilon_{0}$, the dielectric constant of free space; $A$, the electrode area; $d$, the thickness of PZT and; $C$, the capacitance measured by RT66A.

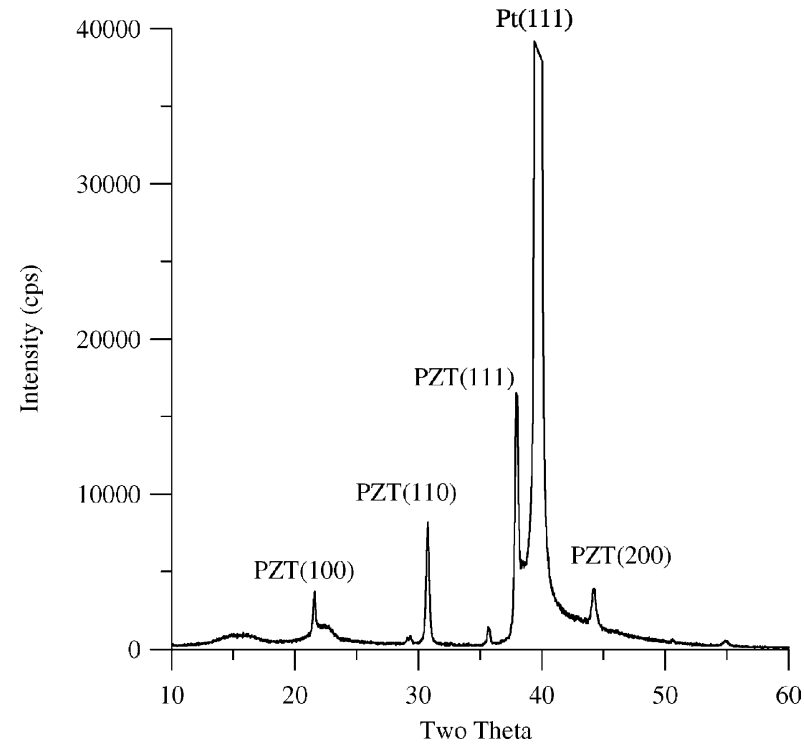

Fig. 15. XRD spectrum of PZT at $700^{\circ} \mathrm{C}$.

The dielectric constant calculated from Eq. (2) is 471.91 . Piezoelectric constants can be estimated from the following equations $[12,18]$ :

$d_{31}=2 Q_{11} P_{\mathrm{r}} \varepsilon_{0} \varepsilon_{\mathrm{r}}$

$d_{33}=2 Q_{12} P_{\mathrm{r}} \varepsilon_{0} \varepsilon_{\mathrm{r}}$

where $d_{31}$ and $d_{33}$ are the piezoelectric constants; $Q_{11}$ and $Q_{12}$ are the electrostrictive constants and; $P_{\mathrm{r}}$, the remnant polarization. The calculated piezoelectric constants are $159.57 \mathrm{pC} / \mathrm{N}$ and $-72.86 \mathrm{pC} / \mathrm{N}$, respectively.

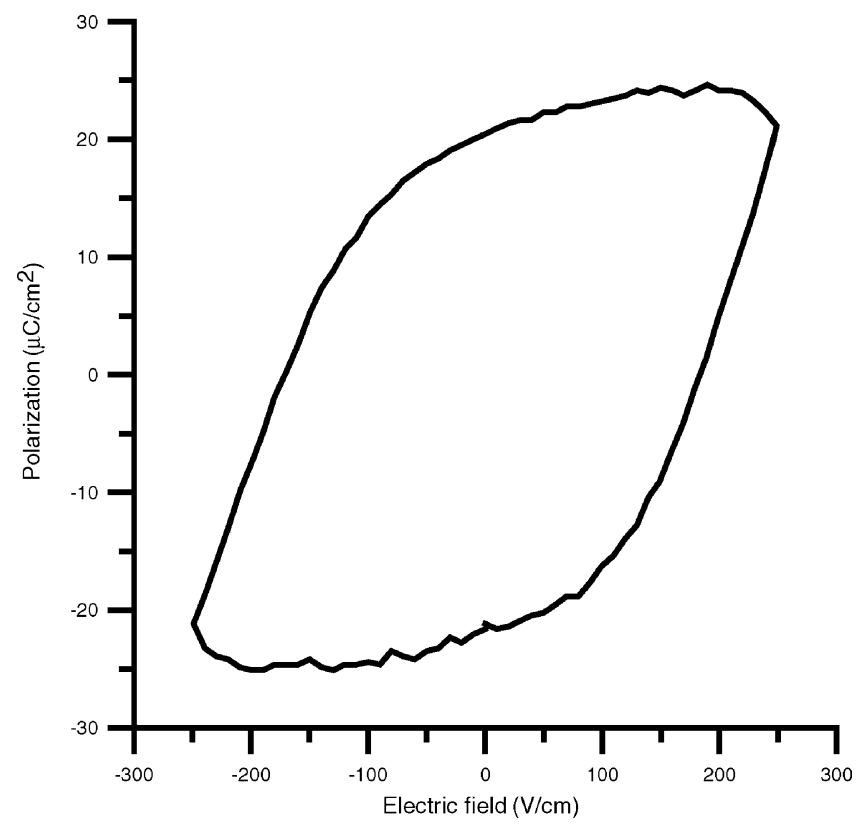

Fig. 16. Hysteresis loop of PZT at $700^{\circ} \mathrm{C}$. 


\section{Conclusions}

It is concluded that thermal effects including recrystallization of platinum and diffusion of titanium greatly depend on the annealing temperature and further, they deform PZT thin film. The deformed PZT leads to hillocks and cracks due to large internal stress. High annealing temperature deteriorates thermal effects, but makes the piezoelectricity better. On the contrary, low annealing temperature worsens the piezoelectricity, but is free from thermal effects. Either increasing the thickness of platinum or adjusting the process parameters of platinum and titanium can effectively mitigate thermal effects at high annealing temperature. Platinum, $2500 \AA$, and $700^{\circ} \mathrm{C}$ annealing temperature is suggested to achieve high quality of PZT.

The measured material properties of PZT annealed at $700{ }^{\circ} \mathrm{C}$ are the following: remnant polarization, $20.448 \mu \mathrm{C} /$ $\mathrm{cm}^{2}$; the coercive field, $183.299 \mathrm{~V} / \mathrm{cm}$; dielectric constant, 471.91; the electromechanical coupling coefficient, 0.672 and; the piezoelectric constants, $d_{31}$ and $d_{33}, 159.57 \mathrm{pC} / \mathrm{N}$, $-72.86 \mathrm{pC} / \mathrm{N}$, respectively.

\section{Acknowledgements}

The authors would like to thank Dr. Yungyu Chen, Kaihsiang Yen, Hunglin Chen, Jinghung Chiou, Tsungwei Huang, Huiwen Huang, Shihchen Chang, Chunyan Chi, of the Institute of Applied Mechanics, National Taiwan University, and Dr. Hsinya Peng, Yubin Chen, of the Department of Mechanical Engineering, National Taiwan University, for their valuable assistance in the experiment. We are grateful for assistance with Sujen Ji of the Advanced Instrumentation Center, National Taiwan University, We would, finally, like to thank the National Science Council Northern Region MEMS Research Center for kindly making their complete research facilities available.

\section{References}

[1] K.D. Budd, S.K. Dey, D.A. Payne, Br. Ceram. Process 36 (1985) 107-121.

[2] G. Yi, M. Sayer, IEEE Process ISAF'92 (1992) 289-292.

[3] Z. Wang, R. Maeda, K. Kikuchi, Process SPIE 3680 (1999) 948-955.

[4] J.S. Wright, L.F. Francis, Mater. Res. Soc. Symp. Process 433 (1996) 357-362.

[5] B.A. Tuttle, R.W. Schwartz, D.H. Doughty, J.A. Voigt, Mater. Res. Soc. Symp. Process 200 (1990) 159-165.

[6] R.A. Lipeles, D.J. Coleman, M.S. Leung, IEEE Trans. Ultrason. Ferr. Freq. Control 38 (1991) 684-689.

[7] G.J.M. Dormans, M.D. Keijser, P.J.V. Veldhoven, Mater. Res. Soc. Symp. Process 243 (1992) 203-212.

[8] L.D. Madsen, L. Weaver, Mater. Res. Soc. Symp. Process 310 (1993) 385-390.

[9] A.R. Zonmorrodian, A. Messariwi, N.J. Wu, Ceram. Int. 25 (1999) 137-140.

[10] T. Ogawa, H. Kidoh, H. Yashima, A. Morimoto, T. Shimizu, Mater. Res. Soc. Symp. Process 243 (1992) 501-506.

[11] C.K. Chiang, L.P. Cook, P.K. Schenck, P.S. Brody, J.M. Benedetto, Mater. Res. Soc. Symp. Process 200 (1990) 133-137.

[12] T. Abe, M.L. Reed, IEEE Process, MEMS'94 (1994) 164-169.

[13] E. Defaÿ, B. Semmache, C. Dubois, M. LeBerre, D. Barbier, Sens. Actuators A 74 (1999) 77-80.

[14] G. Vèlu, D. Rèmiens, J. Eur. Ceram. Soc. 19 (1999) 2005-2013.

[15] P. Muralt, J. Micromech. Microeng. 10 (2000) 136-146.

[16] W.P. Mason, Piezoelectric crystals and their application to ultrasonics, D. Van Nostrand Company, New York, 1950.

[17] T. Ikeda, Foundamentals of piezoelectricity, Oxford University Press, 1990.

[18] K.R. Udayakumar, S.F. Bart, A.M. Flynn, J. Chen, L.S. Tavrow, L.E. Cross, R.A. Brooks, D.J. Ehrlich, IEEE Process MEMS'91 (1991) 109-113. 